\title{
Oesophageal motor response to reflux is not impaired in reflux oesophagitis
}

\author{
R Timmer, R Breumelhof, J H S M Nadorp, A J P M Smout
}

\begin{abstract}
Whether the oesophageal motor response to reflux, as recorded over $\mathbf{2 4}$ hours, is impaired in patients with reflux oesophagitis was investigated. Twenty three patients with oesophagitis (Savary-Miller grades I-IV) and 23 control subjects matched for age and sex underwent 24 hour ambulatory $\mathrm{pH}$ and pressure monitoring. All contractions occurring in the 2 minute period after the onset of each reflux episode were analysed automatically using dedicated computer algorithms. A total of 2085 reflux episodes occurred -1513 in patients and 572 in controls. Oesophageal acid exposure was greater $(\mathbf{p}<\mathbf{0 . 0 1})$ in patients than in controls (mean (SEM) \% time pH $<4$ 13.3 (1.7) and $5.3(0.9) \%$, respectively). The mean duration of the supine reflux episodes was longer $(\mathrm{p}<0.01)$ in patients $(11.2(2 \cdot 8)$ minutes $)$ than in controls $(5 \cdot 1(1.8)$ minutes). In the upright period, no significant differences in the motor response to reflux were found. In the supine period, the patients showed a higher number of reflux induced contractions $(4 \cdot 40$ $(0.61) v 1.62(0.31), p<0.01)$, a higher contraction amplitude $(4.55(0.42) v 2.99(0.71) \mathrm{kPa}$, $\mathbf{p}<0.02)$ and longer contractions $(1.86(0.19) v$ $1.32(0.29)$ seconds, $p<0.05)$. The percentages of peristaltic and simultaneous contractions that occurred in response to supine reflux did not differ between the two groups. In patients with reflux oeosphagitis the motor response of the oesophagus to reflux is not impaired. During the supine period the response is even stronger than in healthy controls.
\end{abstract}

(Gut 1993; 34: 317-320)

Gastro-oesophageal reflux disease has a multifactorial origin. Dysfunction of the lower oesophageal sphincter and impaired oesophageal acid clearance are thought to be the two most important factors in its pathogenesis. Both neutralisation by saliva and oesophageal motor function determine the oesophageal acid clearance. In previous manometric studies, oesophageal motility and acid clearance were found to be impaired in many patients with oesophagitis. ${ }^{1-t}$ The techniques used in these studies were not, however, very physiological. To evaluate the oesophageal acid clearance time a bolus of $15 \mathrm{ml} 0 \cdot 1 \mathrm{~N} \mathrm{HCl}$ was injected into the oesophagus and pressures and $\mathrm{pH}$ were monitored.

The recent development of 24 hour ambulatory $\mathrm{pH}$ and pressure monitoring techniques allows us to study oesophageal motility under more physiological conditions and for prolonged times. Computer assisted techniques make it possible to analyse large quantities of data. ${ }^{5-7}$
The primary aim of this study was to investigate the reflux induced oesophageal motor activity in patients with oesophagitis compared with normal control subjects using a 24 hour ambulatory monitoring technique.

\section{Patients and methods}

Twenty three patients, 18 men and 5 women (mean (SD) age 55.7 (17.0) years), with endoscopically proved reflux oesophagitis (SavaryMiller grades I-IV) and 23 healthy controls, 16 men and 7 women (aged $51 \cdot 2(16 \cdot 8)$ years), underwent 24 hour ambulatory $\mathrm{pH}$ and pressure monitoring using a system developed by our group. ${ }^{68}$ Thirteen patients had grade I oesophagitis, seven had grade II, two grade III, and one grade IV. Grade I was defined as one or more superficial linear erosions, grade II as confluent non-circumferential erosions, grade III as circumferential erosions or exudative lesions, and grade IV as ulceration with stenosis. Nineteen of the 23 patients had a sliding hiatal hernia with a distance between the gastrooesophageal junction and the impession of the diaphragm of more than $2 \mathrm{~cm}$. Patients with secondary or primary peristaltic motor abnormalities such as scleroderma and achalasia were excluded. Five days before the test any medication that might have influenced oesophageal motility or gastric acid secretion was stopped.

Conventional oesophageal manometry was performed in both patients and healthy controls before ambulatory monitoring. A water perfused, three lumen catheter with the openings $5 \mathrm{~cm}$ apart and orientated in three different directions was used. The position of the lower oesophageal sphincter was identified by means of the stationary pull through method.

The 24 hour ambulatory pressure and $\mathrm{pH}$ recording system developed by our group has been described in detail elsewhere ${ }^{68}$ Briefly, the system consists of a microprocessor based portable digital recorder and a personal computer with a dedicated software package written in Turbo Pascal. The system allows continuous recording of two pressure signals (sampled at a rate of $5 \mathrm{~Hz}$ ) and one $\mathrm{pH}$ signal (sampled at a rate of $0 \cdot 125 \mathrm{~Hz}$ ) as well as two marker signals. For $\mathrm{pH}$ recording a combined glass electrode was used (Ingold A G Urdorf, Switzerland, model LOT 440). Intraoesophageal pressure was recorded using a $5 \mathrm{~F}$ custom designed polyurethane transducer catheter (PPG Hellige, Best, The Netherlands). For ambulatory recording, the $\mathrm{pH}$ electrode was positioned $5 \mathrm{~cm}$ above the upper border of the lower oesophageal sphincter, the pressure transducer was positioned with the distal transducer $5 \mathrm{~cm}$ above the lower oesophageal sphincter, and the upper transducer 
$15 \mathrm{~cm}$ above the lower oesophageal sphincter. Both catheters were fixed to the nose with adhesive tape.

During the study, periods of eating and drinking (maximum allowed, eight periods of 20 minutes each) and periods spent in the supine position were registered by the patient in a diary. Episodes of retrosternal pain or heartburn were registered by pushing the event marker and writing down the time, nature, and characteristics of the symptoms. In the portable recorder, only pressure increases greater than $2 \mathrm{kPa}$ and lasting longer than $0 \cdot 8$ seconds were considered contractile events and stored in the digital memory. Dedicated computer algorithms were developed to study all contractions occurring in the 2 minute period after the onset of each reflux episode. A reflux episode was defined as a fall in $\mathrm{pH}$ to a value $<4$ that lasted longer than 24 seconds.

The 2 minute period was chosen on the basis of studies which have shown that in normal subjects, all but $1 \mathrm{ml}$ of a $15 \mathrm{ml}$ bolus of $0.1 \mathrm{~N}$ $\mathrm{HCl}$ is cleared by the first peristaltic contraction without changing the $\mathrm{pH} .^{9}$ In the following 3 minutes, stepwise increases in the distal oesophageal $\mathrm{pH}$ occur with subsequent swallows. Two minute periods that overlapped with preceding episodes were excluded from the analysis. For each 2 minute period the duration of the reflux episode (defined as the time with $\mathrm{pH}<4$ ) and the lowest $\mathrm{pH}$ reached were measured automatically.

All contractions occurring within the 2 minute window were examined using dedicated algorithms that measured: the number of contractions at proximal and distal sensor,

Gastro-oesophageal reflux over the 24 hour period and in upright and supine periods in 23 patients and 23 controls. (Mean values (SEM))

\begin{tabular}{|c|c|c|c|}
\hline & Patients & Comtrols & $p$ \\
\hline \multicolumn{4}{|c|}{ Percentage recording time $\mathrm{pH}<4$ : } \\
\hline Total & $13 \cdot 3(1 \cdot 7)$ & $5 \cdot 3(0 \cdot 9)$ & $\mathrm{p}<0.01$ \\
\hline Upright & $13 \cdot 3(1 \cdot 4)$ & $4 \cdot 6(0 \cdot 8)$ & $\mathrm{p}<0.01$ \\
\hline Supine & $13 \cdot 4(3 \cdot 6)$ & $6 \cdot 4(1 \cdot 7)$ & NS \\
\hline \multicolumn{4}{|c|}{ No of reflux episodes $(\mathrm{pH}<4)$ : } \\
\hline Total & $65 \cdot 3(5 \cdot 2)$ & $24 \cdot 9(3 \cdot 6)$ & $\mathrm{p}<0.01$ \\
\hline Upright & $56 \cdot 8(5 \cdot 2)$ & $14 \cdot 7(2 \cdot 4)$ & $\mathrm{p}<0.01$ \\
\hline Supine & $8 \cdot 5(2 \cdot 5)$ & $10 \cdot 2(2 \cdot 2)$ & NS \\
\hline \multicolumn{4}{|c|}{ Duration of reflux episodes $(\min )$ : } \\
\hline Total & $3 \cdot 0(0 \cdot 3)$ & $3 \cdot 7(0 \cdot 8)$ & NS \\
\hline Upright & $2 \cdot 4(0 \cdot 2)$ & $3.4(0.6)$ & NS \\
\hline Supine & $11 \cdot 2(2 \cdot 8)$ & $5 \cdot 1(1 \cdot 8)$ & $\mathrm{p}<0.01$ \\
\hline
\end{tabular}

number of simultaneous and peristaltic contractions, number of repetitive contractions; mean amplitude of peristaltic contractions, and mean contraction duration. The reflux episodes occurring in the upright and supine periods were analysed separately. In addition, the percentages of time during which the $\mathrm{pH}$ was below 4 for the entire 24 hour period and for the supine and upright periods separately, and the total number of reflux episodes ( $\mathrm{pH}$ drops below 4) were calculated.

All mean ambulatory motility values and reflux variables of the patients were compared statistically with those of the normal control subjects applying the Wilcoxon test for unpaired observations.

\section{Results}

During the 24 hour recording period, 1513 reflux episodes occurred in the 23 patients and 572 in the 23 controls, $1174(74.8 \%)$ and 428 $(77 \cdot 6 \%)$ of which were analysed respectively. The other episodes were discarded because of overlap with preceding or subsequent episodes. As expected, 24 hour oesophageal acid exposure was greater in patients than in controls. In the supine period, however, the difference in oesophageal acid exposure failed to reach statistical significance (Table). Likewise, the number of reflux episodes was significantly higher in the patients than in the controls, but not so in the supine period (Table). The mean duration of the supine reflux episodes was significantly longer in patients than in controls. No significant difference in the duration of the upright reflux episodes was found between patients and controls (Table).

An example of a reflux episode and the oesophageal motor response to it, as recorded in an ambulatory subject, is shown in Figure 1 .

In the first 2 minutes after a ph drop below 4 the average total number of oesophageal contractions observed in the oesophagitis patients was significantly higher than the number occurring in healthy controls (mean (SEM) $5.00(0.41) v$ $3.79(2.53), p<0.01)$. The relative frequency of contraction types (peristaltic, simultaneous, and non-transmitted) was not different between the two groups (Fig 2). The total number of contractions occurring in the 2 minute period after reflux that occurred during daytime (upright
Figure 1: A 4 minute portion of the 24 hour plot of two pressure signals and one $\mathrm{pH}$ signal, showing a single reflux episode with the oesophageal motor response to it. Note the stepwise $p H$ increase with each peristaltic wave.
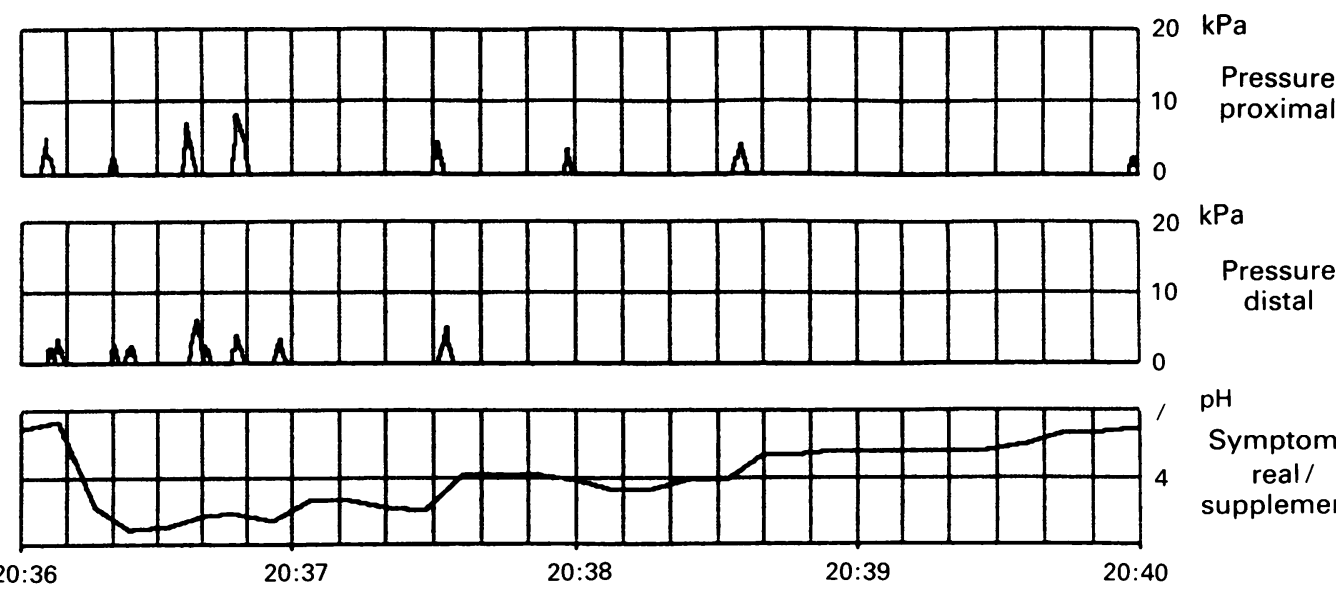

$\mathrm{pH}$

Symptoms

real supplement 
Figure 2: Number and distribution of contraction types (mean (SEM)) occurring in the 2 minute period after gastrooesophageal reflux for the upright, supine, and total 24 hour periods in healthy controls and patients. The total number of contractions occurring during the supine and total 24 hour periods were significantly higher in patients.

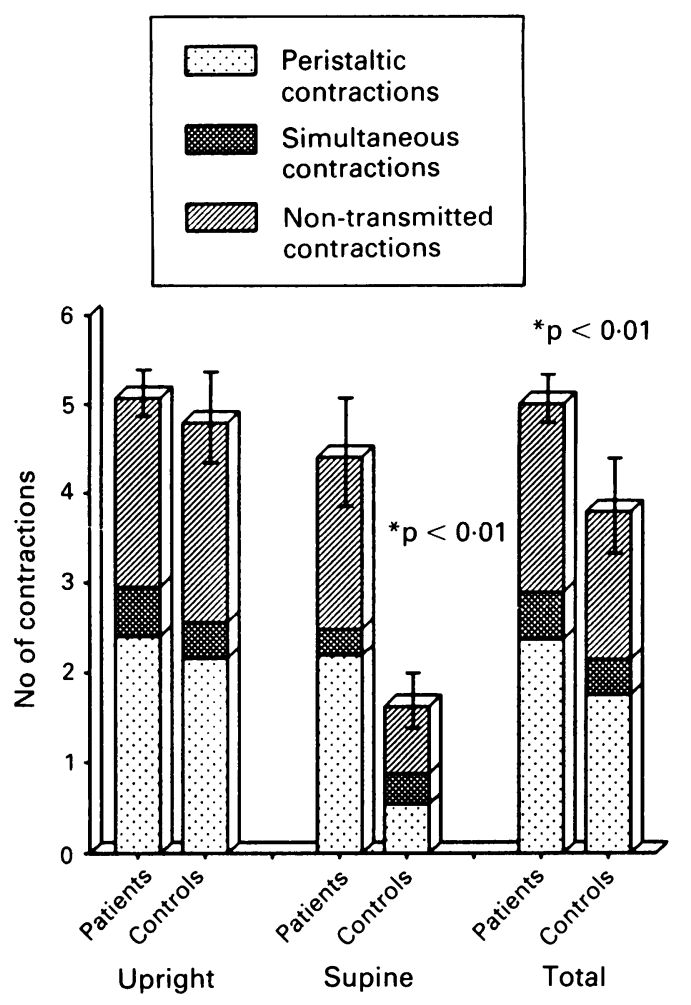

reflux) did not differ between the two groups, nor did the distribution of the contractions (Fig 2 ). In the supine period, there were significantly more contractions during the 2 minute period after a $\mathrm{pH}$ drop below 4 in the patients $(4 \cdot 40$ $(0.61))$ than in the normal subjects $(1.62(0.31))$, but the percentage of peristaltic and simultaneous contractions did not show a statistically significant difference (Fig 2).

During the supine period, the contraction amplitude was significantly $(\mathrm{p}<0.01)$ higher in patients $(4.55(0.42) \mathrm{kPa})$ than in normal controls $(2.99(0.71 \mathrm{kPa})$ (Fig 3). Such a difference was not found for the upright and total 24 hour periods. The duration of the reflux induced contractions that occurred during the supine period was significantly $(\mathrm{p}<0.05)$ higher in the patients $(1.86(0.19)$ seconds) than in the controls (1.32 (0.29) seconds) (Fig 4). Again, no differences were found between patients and controls in the duration of contractions for the upright and total 24 hour periods.

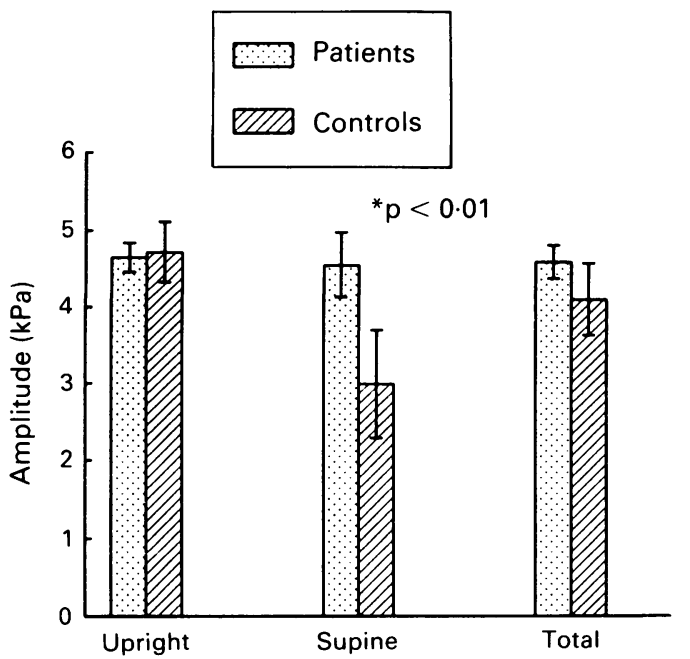

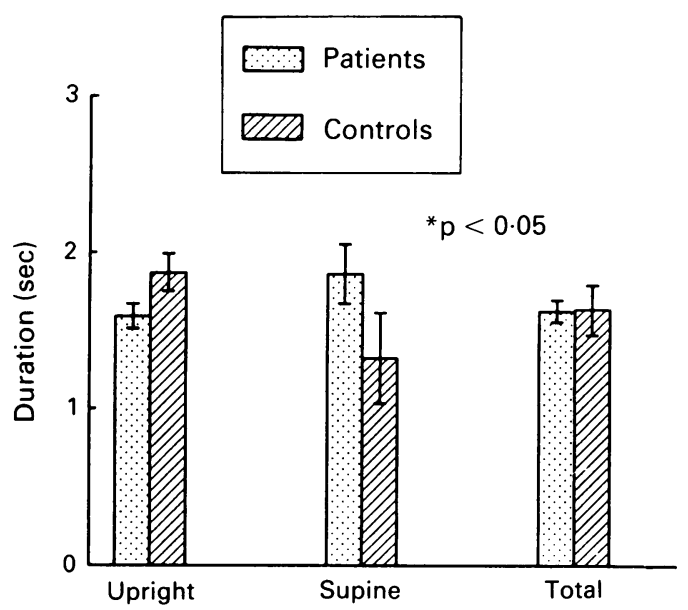

Figure 4: Duration of the contractions (mean (SEM)) occurring in the 2 minute period after reflux in patients compared with normal controls. During the supine period the contraction duration was significantly longer in patients.

\section{Discussion}

Changes in the pressure of the lower oesophageal sphincter and a prolonged oesophageal acid clearance time are usually considered to be the two crucial factors in the pathophysiological process leading to abnormal gastro-oesophageal reflux and oesophagitis. Without a transient lower oesophageal sphincter relaxation or a permanently low sphincter pressure, gastrooesophageal reflux will not occur. After a reflux event, the distal oesophagus has to be cleared of the refluxate.

Two steps can be distinguished in oesophageal clearance, - the first is clearance of the refluxate volume by peristaltic contractions and the second is neutralisation of the remaining acid by saliva. ${ }^{9-11}$ Previous studies have shown, either by means of the standardised acid clearance test or by spontaneous reflux occurring during 24 hour oesophageal monitoring, that acid clearance times are generally two to three times longer in reflux patients than in controls. ${ }^{12-1+}$ It is important, however, to note that the population of reflux patients is heterogeneous, in the sense that some have normal clearance values and others have considerably prolonged values. The two major potential causes of prolonged oesophageal acid clearance are impaired volume clearance and impaired salivary function. ${ }^{15}$ As oesophageal motility has been reported to be increasingly impaired with the increasing severity of oesophagitis, ${ }^{+}$it is likely that this defect will contribute to the impaired volume clearance.

This is the first study that has used 24 hour ambulatory pressure and $\mathrm{pH}$ monitoring to investigate the reflux induced oesophageal motility in patients with oesophagitis and normal control subjects. Dedicated computer algorithms were developed to study all contractions occurring in the 2 minute period after the onset of each reflux episode, defined as a drop in $\mathrm{pH}$ below 4 .

The patients had significantly more reflux episodes and a higher percentage of recording time with $\mathrm{pH}<4$ during the total 24 hour and upright period, but not during the supine period. The mean duration of the supine reflux episodes was significantly longer in the patients, however, compared with control subjects. This agrees
Figure 3: Contraction amplitudes (mean (SEM)) during the 2 minute period
after reflux in patients compared with normal controls. 
with the findings of DeMeester et al ${ }^{13}$ who reported that the mean acid clearance time of 'supine refluxers' was considerably prolonged compared with the values in 15 control subjects.

Paradoxically, during the supine period the reflux induced oesophageal activity was composed of significantly more contractions with a higher amplitude and longer duration in patients with oesophagitis than in the controls. This was not observed during the upright period. In spite of this more vigorous oesophageal motor response, the supine reflux episodes lasted longer in the oesophagitis patients. One of the explanations for this finding could be that this is caused by a different distribution of the contraction types, for example by less peristaltic and more simultaneous and non-transmitted contractions. This was not the case, however, as the percentage of peristaltic and simultaneous contractions occurring in the 2 minute periods did not differ between patients and control subjects. The increased post-reflux contraction rate in the oesophagitis patients might also be caused by a higher swallowing rate, but swallowing was not monitored in this study. As the swallow rate is mainly controlled by the salivary rate, our observations would be consistent with an increased triggering of the oesophago-salivary reflex in the oesophagitis group. As the amplitude of the contractions after supine reflux was higher in the gastro-oesophageal reflux patients, the prolonged reflux episodes cannot be explained by a poor acid clearance caused by peristaltic contractions of low amplitude $(\mathrm{p}<30 \mathrm{~mm} \mathrm{Hg}){ }^{16}$ However, one should take into account the fact that most patients in this study had a low grade oesophagitis.

As previous analysis of motor impairment in gastro-oesophageal reflux disease suggests that the degree of motor impairment becomes progressively more severe with advanced grades of oesophagitis, ${ }^{+}$it is possible that a diminished incidence or amplitude of peristaltic contractions plays a part in prolonged reflux episodes in patients with severe oesophagitis.

On the basis of the observations made in this study we conclude that the prolonged acid clearance time during the supine period found in patients with oesophagitis is not caused by an impaired oesophageal motor response. Reduced neutralisation of acid by saliva during the sleeping hours is also an unlikely explanation for the delayed supine acid clearance observed in this study. It is known that saliva production is decreased at night, ${ }^{17}$ but to our knowledge a difference in saliva composition or saliva production between reflux patients and controls has never been shown. ${ }^{18}$ It is far more likely that the stronger oesophageal response is a (inadequate) reaction to continuing acidification of the distal oesophagus, in particular by re-reflux ${ }^{14}$ from the hernial sac. Nineteen of our 23 patients had a sliding hiatal hernia. This suggests that gravity plays an important role, as we found no differences during day time. Helm et al reported that clearance times were not significantly different, whether measured in the upright or supine postures, suggesting that gravity plays a minor role, but they studied normal individuals, presumably without hiatal hernia. Abnormal clearance has been found to be improved by an upright posture or by bed elevation, suggesting that gravity does help when clearance is abnormal..$^{20}$ If re-reflux plays an important role, then the stronger oesophageal motor response found in our study could well be a reaction to insufficient volume clearance associated with hiatal hernia.

1 Marshall JB, Gerhardt DC. Improvement in esophageal motor dysfunction with treatment of reflux eosphagitis: a report of two cases. Am 7 Gastroenterol 1982; 77: 351-4.

2 Katz PO, Knuff TE, Benjamin SB, Castell DO. Abnormal esophageal pressures in reflux esophagitis: cause or effect. Am 7 Gastroenterol 1986; 81: 744-6.

3 Kahrilas PJ, Dodds WJ, Hogan WJ, Kern M, Arndorfer RC, Reece A. Esophageal peristaltic dysfunction in peptic esophagitis. Gastroenterology 1988; 91: 897-904.

4 Kahrilas PJ, Dodds WJ, Hogan WJ. Effect of peristaltic dysfunction in peptic esophagitis. Gastroenterology 1988; 94: $73-80$

5 Richter JE, Castell DO. 24-hour ambulatory oesophageal motility monitoring: how should motility data be analysed? Gut 1989; 30: 1040-7.

6 Smout AJPM, Breedijk M, van der Zouw C, Akkermans LMA. Physiological gastroesophageal reflux and esophageal motor activity studied with a new system for 24-hour motor activity studied with a new system for 24 -hour recording

7 Emde C, Armstrong D, Bumm R, Kauthold JH, Riecken EO, Blum AL. Twenty-four-hour continuous ambulatory Blum AL. Twenty-four-hour continuous ambulatory
measurement of esophageal pH and pressure; a digital recording system and computer-aided manometry analysis. $\mathcal{F}$ Ambul Monit 1990; 3: 47-62.

8 Breumelhof R, Breedijk M, Akkermans LMA, Smout AJPM. An ambulatory system for 24-hour recording of esophageal motility and pH. F Ambul Monit 1988; 1: 311-20.

9 Helm JF, Dodds WJ, Reidel DR, Teeter BC, Hogan WJ, Arndorfer RC. Determinants of eosphageal acid clearance in normal subjects. Gastroenterology 1983; 85: 607-12.

10 Helm JF, Dodds WJ, Pelc LR, Palmer DW, Hogan WJ, Teeter BC. Effect of esophageal emptying and saliva on clearance of acid from the esophagus. $N$ Engl f Med 1984; 310: $284-8$.

11 Shaker R, Kahrilas PJ, Dodds WJ, Hogan WJ. Oesophageal clearance of small amounts of equal or less than one millilitre clearance of small amounts

12 Booth DJ, Kemmerer WT, Skinner DB. Acid clearing from the distal esophagus. Arch Surg 1968; 96: 731-4.

13 DeMeester TR, Johnson LF, Joseph GJ. Patterns of gastroesophageal reflux in health and disease. Ann Surg 1976; 184: 459-70.

14 Johnson LF. 24-hour $\mathrm{pH}$ monitoring in the study of gastroesophageal reflux. F Clin Gastroenterol 1980; 2: 387

15 Kahrilas PJ. Esophageal motor activity and acid clearance. Gastroenterol Clin 1990; 3: 537-50.

16 Kahrilas PJ, Gupta RR. The effect of cigarette smoking on salivation and esophageal acid clearance. F L.ab Clin Med 1989; 114: 41-8.

17 Schnever I.H, Pigman W, Hanahan I, Gilmore RW. Rate of flow of human parotid, sublingual, and submaxillary flow of human parotid, sublingual, and submaxillar

18 Sonnenberg A, Steinkamp U, Weise A, Berges W, Wienbeck M, Rohner HG. Salivary secretion in reflux esophagitis. Gastroenterology 1982 83: 889-95.

19 Mittal RK, Lange RC, McCallum RW. Identification and mechanism of delayed esophageal acid clearance in subjects with hiatus hernia. (jastroenterologv 1987; 92: 130-5.

20 Stanciu C, Bennett JR. Oesophageal acid clearing: one factor in production of reflux oesophagitis. (iut 1974; 15: 852-7. 